\title{
Relational interdependence between social and individual agency in work and working life
}

\author{
Stephen Billett \\ Faculty of Education \\ Griffith University, Australia \\ Email; s.billett@griffith.edu.au \\ Phone 61-7-3875 5855 \\ Fax 61 - 738756868
}

\begin{abstract}
A greater acknowledgment of relational interdependence between individual and social agencies is warranted within conceptions of learning throughout working life. Currently, some accounts of learning tend to overly privilege social agency in the form of situational contributions. This de-emphasises the contributions of the more widely socially sourced, relational and negotiated contributions of both individual and social agency. As these accounts fail to fully acknowledge the accumulated outcomes of interactions between the individual and social experience that shapes human cognition ontogentically and which also acts to remake culture, they remain incomplete and unsatisfactory. In response, this paper proposes a consideration for the role of individual agency (e.g. intentionality, subjectivity and identity), how it is socially shaped over time and serves to be generative of individuals' cognitive experience, and its role in subsequently construing what is experienced socially. This agency also enacts a relational interdependence with social and historical contributions. Through advancing the conception of relational interdependence, this paper aims to balance views that currently privilege particular social influences in conceptions of learning for work and throughout working life.
\end{abstract}

\section{Interdependency between social and individual agency}

Acknowledging and understanding interdependence between the social and cultural, and individuals' contributions to learning is a contested project within psychology, as it is within sociology and philosophy. Nevertheless, theorising about and understanding the sociogenses of individual and cultural change cannot be advanced without some clearer conception of these relations. My interest in this interdependence has its origins in hairdressers' representations of knowledge that yielded a legacy of situational factors: workplace norms, practices and values that shaped the conduct of their work (Billett 2003). Yet, contributions sourced beyond and prior to participation in the particular workplace were also identified as shaping these individuals' vocational practice, albeit in different ways, thereby influencing how they worked and learnt. More than being merely idiosyncratic, these contributions were identified as having their geneses in events in the hairdressers' life histories or ontogenies. So, beyond the immediate social experience, pre-mediate experiences - those occurring earlier shaped individuals’ cognitive experiences, and how they engaged with and construed subsequent social experiences (Valsiner 1998). These pre-mediate contributions need to be included in accounts that attempt to explain the social geneses of individuals' cognition. From 
these hairdressers' representations of the same work-related tasks, it seems the geneses and exercise of individuals' agency and intentionality - their agentic action - and their social geneses need once more bringing to the foreground. All this suggests a more interdependent account of learning than those privileging situational contributions, such as is provided by communities of practice, activity systems or distributed systems of cognition.

These propositions urge an appraisal of the interdependences between individuals' life histories or ontogenies, and participation and learning in social practices throughout individuals' lives. They also confront the issue of whether individuals can affect substantial cognitive change (learning) on their own, or whether that is only possible with changes in social institutions and practices. This issue is central to understanding how society and culture are remade and transformed, and whether individuals are active participants and initiators in this remaking or are merely only subject to these changes. These issues are particularly salient to understanding learning work-related knowledge, with its dimensions of tried-and-true practices, yet with a need for practitioners to engage with, deploy and remake their work practice in changing circumstances.

There is nothing particularly novel about such propositions. They have been elaborated far earlier (e.g. see Baldwin 1898). However, their consideration at a time when accounts of learning are strongly privileging immediate social contributions is perhaps noteworthy. Indeed, championing the individual within discourses privileging social agency brings risks of being hotly refuted and misinterpreted. For instance, Dewey’s work was expunged from the Soviet education system after he criticised its emphasis on social reproduction (Glassman, 2001). Valsiner is accused of treachery for proposing a key role for the individual within cultural psychology. Ratner (2000) claims that Valsiner's assertion that culture is a set of suggestions that individuals can freely accept, reject or modify as they wish and his replacing socio- historical psychology with co- constructionism is undermining cultural psychology as a corrective to earlier and highly individualised cognitive oriented psychological views.

Here, learning and cultural transformation are held to be a relational interpsychological process - negotiated between the individual and social sources -- that cannot be fully understood without a consideration of individual agency, identity and subjectivity. It is proposed that: (a) individual intentionality and agency have complex social geneses; thereby (b) requiring a more social conception of the individual; and (c) a relational interdependence between the socially constructed individual and the social world is central to understanding ontogenetic development and the remaking of culture. In making its case, the paper is structured as follows. Firstly, the central role of individual agency in human cognition and the 
remaking of culture is advanced. Secondly, the relations between individual agency and social suggestion are then discussed and elaborated in terms of a relational interdependence between them. These ideas are then exercised through considering individuals' constitution of and participation in and learning through their paid work. In conclusion, the duality between social and individual agency is viewed in terms of individualising the social and socialising the individual.

\section{Individual agency and the social genes of human and cultural development}

Understanding how individual agency shapes inter-psychological process is important for at least two reasons. That is, its role in how (i) individuals' learning and cognition develops ontogenetically through agentic action; and (ii) interactions between the social and the individual through which culture (society) is remade and transformed.

\section{Learning and individual agency}

Through interpretation, if not always in conception, in current theorising about learning there is often an uncritical privileging of the immediate social contributions to cognition. There is no space here to elaborate particular situated qualities of distributed cognition, activity systems and communities of practice. However, in brief, distributed cognition is bounded to particular social systems (Salomon, 1997); activity systems comprise pre-specified components to account for particular social practices (Engestrom, 1993); and communities of practice are bounded by their practices and their relations (Wenger, 1998). That is, each account is bonded to particular situations that comprise social practices in which individuals participate, think, act and learn. As such, these accounts are useful for describing, understanding and analysing particular social practice, and, in some ways, individuals' relations to those practices. However, others contest the value of this kind of view claiming it fails to adequately account of how individuals engage with immediate social influences or provide adequate bases for understanding the influences of pre-mediate experiences (e.g. individuals' subjectivities) on that engagement. For instance, distributed theories of cognition have proposed that the individual is but one element in a shared system that shapes human cognition (Pea, Hutchins). Yet, others suggest individuals are not so enmeshed. Both Cobb (1998) and Salomon (1997) have argued that individuals have greater independence. They propose learning as a negotiated process, residing in the interaction between the cognitive and social experience. The cultural psychologist Valsiner (2000) goes further referring to the uniqueness of individuals' cognitive experience - the base by which individuals make sense 
of and reproduce the world. He refers to each experience, even the most mundane, as being in some way unique and special to the individual.

In both anthropological and socio-cultural accounts of learning, individuals' participation in social practice is associated with learning. Lave (1993) suggests that wherever you encounter practice, you also identify learning. Rogoff (1995) emphasises the central role of participation in learning. Across these theories, and consistent with cognitive views (e.g. Anderson, 1993), the consequences of individuals' engagement in goal-directed activities is more than achieving those activities' goals, there is also a cognitive legacy: change shaped by the deployment of cognitive resources (Anzai \& Simon, 1979; Newell \& Simon, 1972). Similarly, both Vygotskian and Piagetian constructivist perspectives, propose that whenever individuals deploy their cognitive resources in tasks and interactions, cognitive change results (Billett, 1996). These and cognitive theories suggest the scope of change is likely to be influenced by the activity's novelty to individuals and the degree of effort they elect to exercise when undertaking the activity (Newell \& Simon, 1972). So the kind of response to the impasse or perturbation that individuals construct from what they encounter likely shapes the kind and extent of cognitive change (Van Lehn, 1998) or intra-psychological outcome. That is, the construction of both the impasses and responses will always be in some ways person-dependent; the actor plays a role. These are not pre-determinable and have conceptual (i.e. how concepts are construed) and procedural (i.e. how the individual thinks and acts) legacies as well as implications for individuals’ subjectivities. Moreover, individuals exercise their person dependence when deciding which problems they engage in and with what degree of engagement: what problems are worth solving (Goodnow, 1990), with the attendant implication for what is changed or learnt through their engagement. So these accounts of learning emphasise the individual and as an actor in relations with the social world.

More than a hundred years ago, Baldwin (1898) proposed individuals' internalisation of the social experience as generative of autonomy, with this autonomy itself being socially constituted. He claimed the sociality of the self cannot be viewed in the similarity of the internalised results of the social experiences, but through personal-psychological phenomena. Accordingly, he proposed that the developing person:

"comes more and more to reflect the social judgement in his own systematic determination of knowledge; and there arises within himself a criterion of private sort which is in essential harmony with the social demand, because genetically considered it reflects it. The individual becomes a law unto himself exercises his private judgement, fights his own battles for truth, shows the virtue of independence and the vice of obstinacy. But he has learnt to do it by the selective control of his social environment, 
and in this his judgement he has just a sense of his social outcome. (Baldwin 1898, pp. 19-20 cited as seen.

Later, Vygotsky also held that in the development of psychological functions, individual agency predominates over social guidance. In referring to child's play, he proposed:

"In play the child is always higher than his average age, higher than his usual everyday behaviour; he is in play as if a head above himself. The play contains, in a condensed way, as if in the focus of a magnifying glass, all tendencies of development; it is as if the child in play tries to accomplish a jump above the level of his ordinary behaviour.... Play is the resource of development and it creates the zone of nearest development. Action in the imaginary field, in the imagined situation, construction of voluntary intention, the formulation of life plan, will motivate -- this all emerges in play." (Vygotsky 1966: 74-75 translated and cited as seen in (Valsiner, 2000)

Beyond individual agency, Vygotsky also refers to the salience of the cultural purposes and goals of activities (e.g. play) and their contributions to individuals' intentionality in their engagement in their zone of potential development. Here, the interdependency of the social and individual is exercised. For Baldwin (1930), a key element of the development of the kind that Vygotsky referred to is the "conscious and social accommodations, imitation, invention and volition ...(p. 4). Yet, imitation is also exercised in particular and intentional ways that reflect the interplay between the social experience and individuals' construction of what is to be imitated. It is not a process individuals engage in with a clear socially-derived articulation of what is required. Otherwise, they would not need to imitate, they would just enact it successfully, as in appropriation. In these ways, the kinds of activities that individuals engage in throughout their lives, and how they elect to engage with these tasks are bases by which individuals actively engage in sense of the social experience. Participation and learning, in this way, are linked ontogenetically to individuals' subjectivities and identities, and also to their development. In appraising individuals' intentionality and agentic action in this engagement it is useful to consider critically the interpsychological process of appropriation.

Appropriation refers to individuals 'making their own' from what they encounter in a social world (Leontyev, 1981). It is often viewed as a desirable process of change as it reflects what is important to individuals as well as what is privileged by social practices. Following Leontyev (1981), Wertsch (1998) distinguishes appropriation from mastery. Individuals appropriate consensually, while mastery is reluctant and superficial learning, and practised only under close social monitoring. Compare the engagement of the enthusiast, with the 
reluctance of the conscript, for instance. Yet, individuals may well appropriate knowledge that is undesirable (e.g. gender or racial bias), short-term (e.g. costly shortcuts), or just plain wrong (e.g. dangerous work practices). This might arise from situational suggestions supporting such learning, which then finds sympathy with an individual's construal. Conversely, individuals might elect to only master crucial aspects of vocational knowledge (e.g. being fair, precise, safe, careful) with consequences that are deleterious for them personally and also for their work practice. Therefore, individually sanctioned interpsychological processes, such as appropriation, need to be viewed critically, in terms of the subjectivities that direct their purposes and outcomes. For instance, Somerville and Bernoth (2001) found that, in different ways, both coalminers and aged care workers came to accept or appropriate workplace injury as part of their occupational identity ( subjectivities). These inter-psychological processes represent a negotiation between individual and social agency. At the very least, individuals select options that shape these processes and conceptualise what is encountered and in ways influenced by their personal histories and agency. The question is the degree by which this personal agency has a social genesis. That is, the extent to which either the enactment of social suggestion or individuals' subjectivity, intentionality and agency reflects individuals' autonomous beliefs and actions. For instance, Somerville (2002) shows how significant events (i.e. a serious workplace accident and health scare) caused two miners to modify their work practices and lives outside work in ways that were inconsistent with the dominant and potentially subjugating culture in a coalmining community. Yet, in turn, these two miners were frustrated when their suggestions to colleagues about safe work practices and healthy lifestyles were rebuffed. This indicates again the relational, yet personal dependent, basis of the contribution of social suggestion (i.e. those who have experienced injury and those that had not), and its contribution to ontogenetic development.

The 'social experience' or suggestion represents what individuals encounter or experience when they engage in interactions with the social world (i.e. social partners, artefacts, situations etc) and access concepts and practices that have a social genesis. The social practice of a workplace, for instance, comprises an institutional fact (Searle 1995) that affords particular kinds of experiences. Yet, these experiences are not available uniformly and their influence will be, at best, partial for some (Berger and Luckman 1966). Its interlocutors will engage in different ways, with different purposes and with diverse conceptual and procedural bases (i.e. their cognitive experience) that are a product of pre-mediate experiences that comprise their ontogenetic development (Billett 2003). Gergen (1994) claims that even when individuals enjoy a common language and cultural backgrounds there arises 
misunderstandings. This is a product of disharmonies to rise from the "continuously unfolding character of human relatedness". He continues:

"As people move through life, the domain of relationships typically expands and the context of any given relationship typically changes. In effect, we are continuously confronted with some degree of novelty--new contexts and new challenges. Yet our actions in each passing moment will necessarily represent some simulacrum of the past; we borrow, we formulate, and patch together various pieces of preceding relationships in order to achieve local coordination of the moment. Meaning at the moment is always a rough reconstitution of the past, a ripping of words from familiar contexts and their precarious insertion into the emerging realisation of the present.”(pp. 269-270)

So, even if individuals' engagement with the social world could somehow be uniform, individuals' construction of the social experience would not be. This is because they actively appropriate knowledge, in ways shaped by their ontogenetically-derived values, concepts, procedures and subjectivities, and as exercised by their agency.

In this way, the social and cognitive experiences represent interdependent dimensions - that are dualistic only in relational terms. Within these relations, personal agency, albeit shaped by pre-mediate and socially derived experiences, play an important role in the engagement in, and the construal and construction of what is suggested by the social experience. So the process of learning is shaped through interactions between social and individual contributions, yet with individuals playing a highly agentic role in those interactions. Moreover, this agency is not restricted to individual learning it also shapes cultural change.

\section{Individual agency and the remaking of culture}

Knowledge of the kind required to engage in paid work, with its cultural and social sources, necessarily has its genesis in the past. This is a great strength, as it comprises proven practices that have evolved over time as new demands emerge and technologies change, and constitutes the occupational knowledge that individuals are required to learn and maintain their currency in throughout their working lives. However, this socially sourced knowledge may have limitations in addressing novel situations or circumstances. This is a salient concern as these practices are continually remade by each generation and as cultural requirements change. To ignore the necessity of human agency in the remaking of this knowledge and to grant primacy to immediately socially derived practices risks denying a key source of its development over time.

This concern about privileging socially derived knowledge was that which fuelled Dewey's criticism of the highly reproductive model of Russian education that had existed 
since Catherine the Great and was then being reified in Soviet Russia (Valsiner, 1988). Rather than being just historically and socially reproductive, Dewey proposed that, education also needed to be responsive to new circumstances and novel requirements, be generative of fresh insights and individuals' contribution, and be tolerant of divergence (Glassman, 2001). Cole (2002), a principal advocate of cultural historical activity theory, shares these concerns suggesting that individual agency stands as a necessary prerequisite for the successful deployment of historically-derived practice to novel circumstances and, hence, its evolution. Recently, he (2002) commented being unable to advise his teacher education students on how they might best survive and teach in turbulent and tough American high schools. In doing so, he conceded that the historically derived and culturally constituted classroom management concepts and practices would fail these novice teachers. Instead, their personal agency and capacities shape the prospect of their success in developing and negotiating effective classroom practices; thereby remaking what constitutes these practices. Cole has been quite consistent with this view. Two decades earlier, he and Griffin (1980) reached a similar conclusion about literacy. Salomon (1997) summarises their conclusion "that while some cultural artefacts, such as those related to literacy, may have some cognitive residues, these residues are in fact quite modest in comparison with the changes brought about in the way people function when literate." (p.126) That is, the potency of socially-generated knowledge, such as literacy, is premised in part on individuals' agency, particularly in its adaptation and deployment to novel circumstances, and hence its remaking.

Appropriation is held to bridge the historical heritage of human beings and each new generation's taking over that heritage (Leonteyev 1981). Beyond selecting and making choices, the "active role of appropriation presents the learner as a constructor of new choices, not constrained to those in immediate circumstances.” (Valsiner 1998: 114) Individuals transform culture as they appropriate practice and carry it forward to the next generation in an altered form (Rogoff 1990) as their creativity builds upon technological transformations and through resolutions to problems they encounter in new times and novel circumstances. Rather than being constrained by the immediate social experience, these constructive processes position individuals as being capable of initiating and formulating their own change and development, albeit influenced relationally by socially derived subjectivities. So vocational practices are not merely reproduced by individuals, they are elaborated, refined and remade as their agency and intentionality engages and interacts with socially-determined tasks and activities. This suggests culture is reproduced and transformed, not through behavioural-like social determinism, but in a complex dialogue between each generation of individuals and the 
social world as meanings are negotiated (e.g. Bhaskar, 1998; Gergen, 1994) and as these meanings change through individuals’ life histories.

Therefore, rather than being solely precipitated by collective events, such as changes to institutional practices and technology, socially generated knowledge and cultural practice also has as its vanguard individuals separately and accumulatively confronting new problems at particular moments in their life histories and at a particular time in history. How individuals elect to remake cultural is of necessity partly a product of their agency and intentionality, as they confront socially constituted factors, or institutional facts (Searle 1995), and negotiate their meaning and impact in particular situations. So, in so far as the immediate experience comprises the enactment of both individual agency and social suggestion and has outcomes for both the individual (i.e. intra-psychological outcomes) and culture (i.e. the remaking of cultural practices), it needs to be seen as a process located in these relations.

It follows that without including and embracing individual agency and intentionality, theories of learning privileging situational factors may well fail to account for individuals' role in transforming culture (e.g. vocational practice), their ontogenetic development, and perhaps most importantly the nature of the relationship that constitutes what are the social contributions to human cognition. Those proposing a strong role for social agency (e.g. Ratner 2000) of course, may reject this view, claiming that such individual autonomy is illusory, and that individual action is always socially determined, or even subjugated. However, it may be more useful to focus on the relational bases and how this exercises and enunciates the social.

\section{Relations between the individual and the social world}

Perhaps the most salient purpose for bringing the individual to the foreground in conceptions of learning and the remaking of cultural is to consider the interdependence between the individual and the social, including socially-derived subjectivities. Within sociology and philosophy, the relations between structure and agency are well-exercised and perhaps more mature in their deliberations than those in psychology (Gergen 1994). Both philosophy and sociology offer highly structural accounts in which individual agency is seen as illusory (e.g. Bourdieu, Durkhiem), accounts that grant individual autonomy (e.g. Goffman, Rousseau, Weber) and those that acknowledge interaction between the two (e.g. Giddens, Bhaskar, Berger and Luckman). Highly structured views, such as Foucault's earlier position, for example in Discipline and Punishment (1979) emphasise social subjugation of the individual and renders them as mere placeholders in social networks (Mansfield, 2000) because they are enmeshed or saturated by social suggestion (Gergen 2000) and in ways diminishing their personal autonomy. Bourdieu (1991) refers to a battery of dispositions, comprising a habitus 
that orientate individuals' actions. He cites, for example, how social practice determines both conscious action and unconscious performance, as in individuals’ dialects. Similarly, Foucault (1979) suggests individuals are subject to pervasive social press and are 'placed under' or subjected to the influence of cultural norms and practices, that shapes and constrains the boundaries of what or in which space individuals' exercise discretion. So, in these views, individuals’ subjectivities and identities are structurally derived and leave little space for personal autonomy in thinking and acting (Davies, 2000). Here, the idea of the self-regulating and self-subjugating 'enterprising self' (Du Gay 1996) is held to characterise how workers engage with the churning and transformational nature of contemporary workplaces. Personal identity and subjectivity are essentially socially derived, as with accountants in a large accountancy practice, who shaped their behaviours, performances and even life outside work to secure and advance their place within the workplace (e.g. Grey 1994).

Conversely, others suggest individuals are less constrained by these structures (e.g. Rousseau, 1968, Goffman 1959). According to these views, individuals have personal autonomy and are able to exercise their agency in a socially constructed world. Such perspectives are privileged in humanistic conceptions of subjectivities and identity and the exercise of unencumbered autonomy and agency (Davies 2000). Then, there are others proposing a more relational view of structures as being facilitative. The philosopher Bhaskar (1998) even claims that sociology is not about collective action, but relations between individuals and social practices. Giddens (1984) through his concept of structuration analogously proposes a key role for personal agency in the social structuring of knowledge. By acknowledging interactions (interdependence) between social structures and individuals he links individual intentionality and their subjectivity. Foucault (1984) refers to individuals being able to take care of themselves, proposing human desire as an agentic property that can guard against unbridled social subjection. In ways analogous to the Piagetian concept of maintaining equilibrium, Giddens (1991) suggests the problem for the self is in maintaining its security in a culture that threatens its stability and the reference points for this stability, in a time of modernity characterised by anxiety causing changes in, for instance, how people work and secure themselves in paid employment. Yet, Fenwick (1998) proposes that while permitting a role for individuals, this view positions them as anxiety ridden and their agency restricted to reflexive relations with culture. In her study of small business operators, and in Billett and Pavlova's (2003) study of workers negotiating change, there emerges evidence of them being quite agentic: exercising their sense of selves or being themselves in negotiating their place in transforming work situations. That is, they act independently from the social suggestions. This evidence suggests that rather than being subjugated, or the relations 
between the individual and the social being mutual or reciprocal, there is a need to view them as being relational and by different degree entwined and interwoven.

Conceptions of such relations and individuals' agentic role with them have longstanding conceptual foundations. Cartesian dualism is often held as the epitome of the separation between body and the mind. Its demise has been heralded as the basis for reconciling the human mind with the social world (e.g. Scribner, 1997/1990) or that 'beyond the skin’ as some prefer (e.g. Hutchins, 1991; Wertsch, 1991). However, ultimately, Descartes was a non-adherent to what became Cartesian Dualism. Instead, he refers to the duality between body and mind. In his last work, Passion in the Soul (1649), he claimed a substantial union exists between the mind and the world beyond. Significantly, he saw human passion as a key link between the external world and the mind, that is, the basis for their relationship. Passions are used by Descartes deliberately to account for influences outside the body and beyond physiological responses (i.e. pain, hunger) (Copleston, 1994; Haldane \& Ross, 1971). Moreover, for Descartes beatitude was the "tranquillity or contentment of soul tenable in this life by one's own efforts" (Copleston, 1994). That is, the self in action with the world constitutes this desirable state. Similarly, Schopenhauer (1883 cited in Cottingham 1996) also referred to human will as means by which the mind is linked to the external world. Moreover, in his later work, Foucault (1984) came to see desire as a socially-derived subjectivity and individuals' response to it as being emblematic of their capacity to be agentic. In this way, these authors emphasise the phenomena that in contemporary psychological terms has come to be described as human intentionality or agency (e.g. Malle et al 2001).

Perhaps significantly, Scribner (1997/1990) suggested that, having overturned Cartesian dualism, the task for psychology is to understand the relations between the social world and individuals' behaviour. She characterised these relations as being irreducible, claiming that to separate them was akin to attempting to separate sodium and chlorine yet still retain its saltiness (Martin \& Scribner, 1991). Rogoff (1990) and Wertsch (1998) also refer to, respectively, the inseparability and irreducibility of individuals’ efforts and social interests including the broader cultural milieu. However, accounts such as situated cognition, distributed cognition, activity systems (Engestrom 1993), communities of practice (Lave \& Wenger 1991) run the risk of privileging situational determinism, at a cost to considerations of individual agency and broader social and cultural influences. Just as behaviourism denied human consciousness (Taylor, 1985), accounts that emphasise situational determinism risk denying human intentionality, agency, and identity. Therefore, finding a pathway between social determinism and highly individualistic accounts of cognition is important in understanding their relationship (Miller \& Goodnow, 1995). 
Valsiner (1994) and Bhaskar (1998), while acknowledging the breadth and ubiquity of social influence, emphasises the relatedness between individuals' interests and goals, and those comprising the social suggestion. This shapes how individuals elect to engage in interpsychological processes, such as appropriation and mastery, as discussed earlier. Valsiner (1994) holds relatedness ranges from total involvement to being wholly disengaged.

Similarly, Berger and Luckman propose, "socialisation is never completely successful. Some individuals inhabit the transmitted universe more definitely than others. Even among the more or less accredited inhabitants, there will be idiosyncratic variations in the way they conceive the universe” (1966 .p.24). Yet, what is proposed as idiosyncratic by these authors is seen here as being the product of individuals’ personal histories. So rather being reciprocal, these relations are relational. And rather than dualisms they are dualistic: inclusively separated parts of the system between which function processes occur (Valsiner \& van de Veer 2000: 206).

The relational nature of these interdependencies is identifiable in the negotiations between two sets of continuities. Firstly, the social practice likely affords opportunities in ways directed towards securing its continuity and development or those of interests within it. Social practices such as workplaces, educational institutions and community groupings provide opportunities directed towards advancing their goals and practices or interests within them (Billett, 2002a, 2002b). However, individuals’ participation in social practice is also mediated by their intentions for continuity and development, albeit shaped by subjectivities about cultural or occupational identity. For example, a counsellor was able to transform his work practice, partially afforded by the professional standing of his work, and in doing so secured personal and professional goals; whereas another worker was constrained by consensus based in making which denied her the autonomy that the counsellor enjoyed (Billett, Barker, \& Hernon-Tinning, 2004). In the former, some key workplace practices and continuities were transformed by individual action. In the latter example, the practices constrained both transformation and individual agency. The interplay between these two sets of continuities and the degree of their consonance or contestation underpins the relations that also constitute the parameters for its remaking. Therefore, an instance of social practice, such as a classroom or workplace, needs understanding in terms that include: (i) participants' interests, identities and subjectivities; (ii) the degree of consonance between these; and (iii) the goals and continuities of the social practice, including the possibility for an active role in its remaking. This interdependence and dialogicity is inherent in the process of meaning making and construction of knowledge. Newman et al. (1989) claim that Vygotsky's greatest contribution was not in linking the external and internal, but in emphasising the dialectic 
between the inter- and intra-psychological. Similarly, Suchman (1997) in considering humanmachine interactions suggests.

"The point is not to have the price of recognizing the agency of artefacts be the denial of our own. Agency - and associated accountabilities - reside neither in us or in or in our artefacts, but in our inter-actions.”

Valsiner (2000) and Gergen (1994) emphasises not just the individual coming to share their social partners' understanding (as in intersubjectivity), but to shape and transform that understanding in the face of new experience. Setting aside a socially deterministic view, and de-emphasising Foucaldian-like subjugation Valsiner (1998) proposes "most of human development takes place through active ignoring and neutralisation of most of social suggestions to which the person is subjected in everyday life" (p. 393). This is essential to buffer individuals' personalities against the demands of constant social suggestions that comprise the immediate experience. He continues,

"Hence, what is usually viewed as socialisation efforts (by social institutions or parents) is necessarily counteracted by the active recipients of such efforts who can neutralise or ignore a large number of such episodes, aside from single particularly dramatic ones."

Taylor (1985) claims that humans are not alone in having desires and motives in making choices. Yet unlike other animals, humans appear to have the capacity for reflective self-evaluation manifested in second order desires. These desires are those shaped over time as in subjectivities. So rather than merely being driven by external pressures and sources, individuals have the capacity to be reflective and evaluative about their societal subjugation, particularly the immediate suggestion. Therefore, even when confronted with strong social press, the negotiated process of meaning making deflects or directs individuals into a course of action that may be contrary to the social suggestion. Through exercising her agency, Hodges (1998) came to reject the kinds of values that underpin an institutionalised view of childcare education. This led her to disassociate and dis-identify with a social practice in which she had participated. Similarly, Fenwick (1998) identifies women’s exercise of agency as they find meaning in their work, which extends well beyond merely selecting options of what is afforded by workplaces. In a workplace that introduced surveillance procedures, individual workers were still able to exercise degrees of freedom within the constraints of these procedures (O’Doherty and Willmott 2001). Similarly, a hairdressing salon affording a strong, pervasive and particular form of social guidance that directed the activities in the salon (e.g. who did what tasks, how they were done, on what basis individuals were allowed to talk) did not result in the hairdressers' uncritical acceptance of these demands (i.e. appropriation). 
Nor were there uniform responses in their cognitive representations of activities and preferences, despite the strong social press (Billett, 2003). These instances are examples of the exercise of human intentionality and by degree of what Foucault describes as the care of the self (1984). Indeed Dawe (1978 cited in Knights and Willmott 1989) claims:

"In every testimony to the experience of the humanising pressures of modern industrial society, there is also a testimony to a contrary sense of self, of personal identity, of being human; of what it is or might be like to be in control of our own lives, to act in and upon the world, to be active human agents. So, in the name of our personal identities, our personal hopes and projects and longings, in the name of ourselves, we resist." (pp.364-365)

So human agency operates relationally within and through social structures, yet is not necessarily subjugated by them. Individuals may elect to be subjugated by particular social suggestion and in ways describable as appropriation. So through these relations, individuals are always socially related, albeit through their subjectivities or more immediate experiences (Bhaskar, 1998). Therefore, any action that individual agency initiates, including action to transform society, always occurs from a social basis, albeit through an interdependency that is relational. Yet, as Berger and Luckman (1966) concluded, and Valsiner (1994) proposes the degree of social subjection encountered in the immediate experience is not uniform or uniformly impelling. It represents a suggestion that may be weaker or stronger dependant on its influence or emphasis and significance to the individual. Everyday, individuals engage with or transgress any number of social practices, mostly obliviously. This is because they are not key interlocutors. There are social (communities of) practice in the canteen, shop, service station that individuals' engage with fleetingly and as highly peripheral participants. There are social (communities of) practices in which we engage with perhaps a higher degree of interdependence (e.g. family, our workplace). So just as the social suggestion is not uniform or easily extended, so too its engagement by individuals might be at best partial, perhaps because the press may be unknown and unrecognised. For instance, adolescents' social fads may be lost on their parents. Yet, as with appropriation, we are capable of being voluntarily enmeshed by socially-derived suggestions particularly when they are consonant to our subjectivities.

\section{Relational interdependence at work}

One way to exercise and illuminate the role of individual agency and its relational interdependence with the social world is to consider how individuals think about and participate in paid work. In research that sought to understand learning in workplace settings, 
individuals were identified as engaging in a highly committed manner in work that many would view as being low status or lowly paid (e.g. coal production workers, process workers, call centre workers)(Billett, 2002b). Through serial interviews, these workers often reported dissatisfaction with their workplace affordances (e.g. conditions and the actions of fellow workers and employers). Yet, they also claimed in those interviews and demonstrated, through observation, high levels of commitment to and interest in their work. The sense is of workers who take their work seriously, want to do a good job and be accepted by their peers as good performers. That is, they engage in this work in ways that exercises their agency, yet directed to their subjectivities (e.g. approval of peers) and identity (e.g. seen as being a good team worker). How should we think about these individuals? Are they cultural dopes, who have been duped into self-exploitation and false consciousness as structural accounts suggest? Or are these individuals intentionally exercising agency consistent with their identities and subjectivities? If the former view is taken, it suggests that we should value individual's vocational practice and engagement in terms of its extrinsic worth (e.g. its status, standing, purposes). That is, some forms of work are highly paid, have high status and are viewed worthy of individual's engagement and exercise of their interest, passion, desire and agency, and some are not.

The sociologist Wright Mills (1973) claims that "For most employees, work has a generally unpleasant quality. If there is little Calvinist compulsion to work among propertyless factory workers or clerks, there is also little Renaissance exuberance in the work of the insurance clerk, freight handler, or department store saleslady”. This view is consistent with what some contemporary accounts propose about service work (e.g. Rifkin 1995), such as call centre workers. Yet, call centre work can be complex, varied, subject to skilfulness and, the operators working in a collaborative and agentic way (Billett, 2002b). It can have many qualities that elsewhere enjoy higher pay and status. So valuing work solely by its socially suggested value seems precarious. Salary levels and status certainly do not assure social or personal worth. From a values perspective, it might be claimed that auditors' work is nonemancipatory and, therefore, not worthy of higher education. This view suggests that individuals’ work should be valued on an objectified measure of social standing or worth. However, to somebody from a low socio-economic background or who achieved poorly at school becoming an auditor might be personally or socially emancipatory. Although doctors, lawyers and accountants are seen as desirable occupations and have potentially positive social purposes (like call centre workers), they are not immune from bad practice and exercise of self-interest. Similarly, although the degree of discretion workers are permitted is often held as being highly desirable it too can be a perilous measure. A trade union worker although 
granted high levels of discretion in work, while closely aligned to her personal goals and values, was being exploited by the breadth and discretion her work practice afforded her (Billett et al., 2004). Even though her work was of social worth, being directed to social justice, and she enjoyed significant discretion in the scope of the work, it made almost intolerable demands upon her.

To propose that conceptions of worthwhile work are confined to that which is highly paid, of assumed social benefit, likely renders perhaps the majority of workers as engaging in worthless pursuits, as Wright Mills (1973) suggests. However, across different kinds of work individuals want to be seen as performing effectively, often gaining a sense of identity and sense of self through their work and its relationship to their lives in the community outside the workplace (Pusey 2003). That is, their sense of self and identity is tightly linked to how they think about and engage in their work. In one study, a group of males were facing redundancy. Given the shortage of work in the region that attracted that level of pay and carried similar masculine qualities, the threat to these workers was more than loss of income, it included their sense of self -- their standing as males in the community (Billett 2002a). In another study, while claiming that their work was only a means to an end, workers elaborated in great detail about how their work was central to their identity, sense of self and standing in the community (Billett \& Pavlova 2003).

Therefore, it seems no more problematic to value conceptions of work for its worth to individuals' identity and subjectivities than to more socially objectified and commodified purposes, such as the societal standing and level of remuneration. Such a view is consistent with that advanced by Dewey (1916) who proposed vocations as being directions in life, a personal journey linked to individuals' goals and interests. He proposed that all kinds of human activity should be seen as being potentially valid vocations, from the practice of professionals, to the trades, to the act of parenting. Their validity resides in what they mean to and how they suit individuals engaged in them: their sense of self and identity. For Dewey the opposite of vocation is not leisure, but activity that is aimless, capricious and involve dependence on others, rather than cumulative achievement for the individual (Quickie 1999). To engage in paid pursuits that they were not suited to or interested in was a waste of individuals’ potential and is akin to slavery, he argues. Yet, advancing individual agency as a means through which individuals can be fulfilled, is not to absolve social problems such as inequity, nor is it about creating a false sense of equity, democracy and fulfilment and denying alienation (Ratner, 2000). It is about humanising social relations and social structures, and locating a legitimate and appropriate role for individuals in directing their cognition, learning and the remaking of culture. 


\section{Individualising the social - socialising the individual}

The attempt here is an initial drafting and outlining of some bases by which we might consider interdependence in the relational duality between individuals and their social worlds in the learning of and developing further their vocational practice. It proposes individuals are subject to the social world, in its immediate and pre-mediate forms, through a relational interdependence. While side-stepping the task of reconciling distinct views about structure and agency, a more socially inclusive, engaged and sympathetic view of the individual is proposed. The individual is often characterised as being oppositional to the social. Cognitive psychological accounts are frequently and perhaps legitimately presented or interpreted in ways that represent individuals and their minds as being asocial, or without social reference points (Gergen 1994). In social cultural critiques of individualistic orientations to psychological theorising much is made of this claim (Bruner, 2001). However, through incorporating the pre-mediate influences of cultural practices over time (e.g. subjectivities) as well as the immediate social experience (e.g. situational contributions), and post-mediate experiences (i.e. how subsequent experiences are constituted) what comprises the individual in psychological accounts, can be re-constituted to acknowledge that individuals' cognitive experience is shaped interdependently through their participation in different and diverse instances of social practice throughout their ontogeneses (Billett, 1998). Or, as (Valsiner, 1998:2) proposes, that the individual "simultaneously maintains his or her autonomy relative to the given social context, and has become the way he or she is through the history of such relations."

The concept of development over a lifespan or ontogeny positions the individual centrally in the ongoing and related interdependence between the cognitive and the social experience. This includes the potential for subjection to or rebuffing of cultural and social suggestions that individuals engage with in different ways and intensity. Individuals' idiosyncratic cognitive experience can then be understood as a social outcome (Baldwin 1930): a history of social experiences. This offers a more reflexive way of addressing the question of whether change is premised on individual or social factors by proposing that changes are wrought in complex, yet relational interdependences between the two. In the hairdressing salons, there were particular pattern of procedures that constrained the hairdressers' selection of possible procedures - ' what we do here is'. However, more authorised individuals (i.e. owners and managers) exercised solutions outside of the salons' norms (Billett, 2003). That is, they were socially sanctioned and legitimised to exercise their agency in their choice of procedures, which were public and observable, in ways that junior 
staff were not permitted. Regardless, all the hairdressers were able to exercise their agency in the negotiations with their clients the selection of options within the prescribed hair treatments. Evident in their choice of treatments were the individually preferred procedures whose preferences was sourced in earlier experiences (i.e. the pre-mediate).

Therefore, the individual can be seen as being socially shaped ontogenetically, albeit in ways rendered unique by their personal histories of self-construction. This may help in elaborating and understanding how the individual and social agency interact (relationally) with its consequences for ontogenetic development, and the generational transformation of societies and communities. Yet, even when there is sympathy between the cognitive and the social experience, as in appropriation, there is likely to be misunderstanding, misinterpretation and differences in constructs. Human agency and cognition is neither uncritical nor limitless, nor is it machine-like or wholly 'rational'. Instead, it is selective, discriminating and mediating, yet at times just plain woolly just like our intentions and energies. Yet, while the degree of individual autonomy in transforming knowledge remains contested, it has been proposed here that more than being able to select from social suggestion, individuals' agentic actions likely has the capacity to shape their development and remake cultural practice in transformative ways.

In sum, relations between individual and the social world might best be understand as those between ontogeny and history, operating in parallel and through negotiation where the immediate and pre mediate coalesce and shape the post mediate experience. It is these relations that are continually engaged in remaking and reproducing cultural and social practice, as in vocational practice and learning.

Acknowledgements. The author acknowledges the helpful comments of the two reviewers whose suggestions guided the revision and further development of this paper.

\section{References}

Anderson, J. R. (1993). Problem solving and learning. American Psychologist, 48(1), 35-44.

Anzai, Y., \& Simon, H. E. (1979). The theory of learning by doing. Psychological Review, 86, 124140.

Baldwin, J. M. (1898). "On Selective Thinking." The Psychological Review V(1): 1-24.

Baldwin, J. M. (1930). James Mark Baldwin. In C. Murchison (Ed.), A history of psychology in autobiography (pp. 1-30). Worcester MA,: Clark University.

Berger, P. L., \& Luckman, T. (1966). The Social Construction of Reality. Harmondsworth, Middlesex: Penguin.

Bhaskar, R. (1998). The possibility of naturalism. London: Routledge.

Billett, S. (1996). Situated learning: Bridging sociocultural and cognitive theorising. . Learning and Instruction, 6(3), 263-280.

Billett, S. (1998). Ontogeny and participation in communities of practice: A socio-cognitive view of adult development. Studies in the Education of Adults, 30(1), 21-34. 
Billett, S. (2002a). Critiquing workplace learning discourses: Participation and continuity at work. Studies in the Education of Adults, 34(1), 56-67.

Billett, S. (2002b). Workplace pedagogic practices: Co-participation and learning. British Journal of Educational Studies, 50(4), 457-481.

Billett, S. (2003). Sociogeneses, Activity and Ontogeny. Culture and Psychology, 9(2), 133-169.

Billett, S., Barker, M., \& Hernon-Tinning. (2004). Participatory practices at work. Pedagogy, Culture and Society. 12 (2) 233-257

Billett, S. \& Pavlova, M. (2003)* Learning through working life: individuals' agentic action, subjectivity and participation in work. $11^{\text {th }}$ Annual International conference on postcompulsory education and training: Enriching learning cultures, (vol 1 - pp. 72-80), 1-3 December, Gold Coast

Bourdieu, P. (1991). Language and Symbolic Power (Edited by J.B. Thompson). Cambridge: Polity Press.

Bruner, J. (2001). Foreword. In B. F. Malle \& L. J. Moses \& D. A. Baldwin (Eds.), Intentions and Intentionality: Foundations of Social Cognition (pp. ix - xii). Cambridge, Massachusetts: The MIT Press.

Cobb, P. (1998). Learning from distributed theories of intelligence. Mind, Culture, and Activity, 5(3), 187-204.

Cole, M. (2002). Building Centers of Strength in Cultural Historical Research. Paper presented at the Annual Meeting of the American Education Research Association, New Orleans.

Copleston, F. S. J. (1994). A history of philosophy. Volume IV: Modern philosophy. New York: Doubleday.

Cottingham, J., Ed. (1996). Western Philosophy: An anthology. Oxford, Blackwell.

Davies, B. (2000). A body of wrtiting 1990-1999. New York: Altamira Press.

Dewey, J. (1916). Democracy and Education. . New York: The Free Press.

Engestrom, Y. (1993). Development studies of work as a testbench of activity theory: The case of primary care medical practice. In S. Chaiklin \& J. Lave (Eds.), Understanding Practice: perspectives on activity and context (pp. 64-103). Cambridge, U.K: Cambridge University Press.

Fenwick, T. (1998). Women's Development of Self in the Workplace. International Journal of Lifelong Learning, 17(3), 199-217.

Foucault, M. (1986). The Care of the self:The History of Sexuality, vol 3. Harmsworth, Penguin.

Foucault, M. (1979). Discipline and punishment. New York: Vintage Books.

Gergen, K. J. (1994). Realities and Relationships: Soundings in social construction. Cambridge, Mass: Harvard University Press.

Gergen, K. J. (2000). The Saturated Self: Dilemmas of Identity in Contemporary Life. New York, Basic Books.

Giddens, A. (1991). Modernity and self-identity : Self and Society in the Late Modern Age. Stanford, Stanford UNiversity Press.

Giddens, A. (1984). The constitution of society. Cambridge: Polity Press.

Glassman, M. (2001). Dewey and Vygotsky: Society, Experience, and Inquiry in Educational Practice. Educational Researcher . 30(4), 3-14.

Goodnow, J. J. (1990). The socialisation of cognition: what's involved? In J. W. Stigler \& R. A. Shweder \& G. Herdt (Eds.), Cultural Psychology (pp. 259-286). Cambridge, UK: Cambridge University Press.

Grey, C. (1994). "Career as a project of the self and labour proces discipline." Sociology 28(2): 479497.

Haldane, E. S., \& Ross, G. R. T. (1971). Philosophical works of Descartes: Dover Publications.

Hodges, D.C. (1998) Participation as Dis-identification With/in a Community of Practice. Mind, Culture and Activity, 5 (4), 272-90.

Hodkinson, P., \& Bloomer, M. (2002). Learning careers: Conceptualising lifelong work-based learning. In K Evans \& P. Hodkinson \& L. Unwin (Eds.), Working to Learn: Transforming learning in the Workplace (pp. 29-43). London: Kogan Page.

Hutchins, E. (1991). The Social Organization of Distributed Cognition. In L B Resnick \& J. M. Levine \& S. D. Teasley (Eds.), Perspectives on socially shared cognition (pp. 283-307). Washington DC: American Psychological Association. 
Lave, J. (1993). The practice of learning. In S. Chaiklin \& J. Lave (Eds.), Understanding practice: Perspectives on activity and context (pp. 3-32). Cambridge, UK: Cambridge University Press.

Lave, J., \& Wenger, E. (1991). Situated learning - legitimate peripheral participation. Cambridge, UK: Cambridge University Press.

Leontyev, A. N. (1981). Problems of the development of the mind. Moscow: Progress Publishers.

Malle, B. F., Moses, L. J., \& Baldwin, D. A. (2001). Introduction: The Significance of Intentionality. In B. F. Malle \& L. J. Moses \& D. A. Baldwin (Eds.), Intentions and Intentionality: Foundations of Social Cognition (pp. 1-26). Cambridge, Massachusetts: The MIT Press.

Mansfield, N. (2000). Subjectivity: Theories of the self from Freud to Haraway. Sydney: Allen and Unwin.

Martin, L. M. W., \& Scribner, S. (1991). Laboratory for cognitive studies of work: A case study of the intellectual implications of a new technology. Teachers College Record, 92(4), 582-602.

Meade, G. H. (1934). Mind, Self \& Society: Works of George Herbert Meade (Vol. 1). Chicago: University of Chicago Press.

Miller, P. J., \& Goodnow, J. J. (1995). Cultural practices: Towards an integration of culture and development. In J J Goodnow \& P. J. Miller \& F. Kessel (Eds.), Cultural Practices as Contexts for Development (Vol. 67, pp. 5-16). San Francisco: Jossey Bass.

Newell, A., \& Simon, H. A. (1972). Human problem solving. Englewood Cliffs, N.J: Prentice Hall.

Newman, D., Griffin, P., \& Cole, M. (1989). The construction zone: Working for cognitive change in schools. Cambridge, UK: Cambridge University Press.

O'Doherty, D. and H. Willmot (2001). "The question of subjectivity and the labor process." International Studies of Management and Organisation 30(4): 112-133.

Pusey, M. (2003). The Experience of Middle Australia. Cambridge, UK: Cambridge University Press.

Quickie, J. (1999). A curriculum for life: Schools for a democratic learning society. Buckingham, Open University Press.

Ratner, C. (2000). Agency and culture. Journal for the Theory of Social Behaviour, 30(413-434).

Rifkin, J. (1995). The end of work: The decline of the global labor force and the dawn of the postmarket era. New York, NY, Ajeremy P. Tarcher/ Putnam Book, G.P. Putnam's Sons.

Rogoff, B. (1990). Apprenticeship in thinking - cognitive development in social context. New York: Oxford University Press.

Rogoff, B. (1995). Observing sociocultural activity on three planes: Participatory appropriation, guided participation, apprenticeship. In J. W. Wertsch \& A. Alvarez \& P. del Rio (Eds.), Sociocultural studies of mind. Cambridge, UK: Cambridge University Press.

Rousseau, J. J. (1968). The Social Contract. London: Penguin.

Salomon, G. (1997). Distributed cognitions: Psychological and educational considerations. Cambridge, UK: Cambridge University Press.

Scribner, S. (1997/1990). A sociocultural approach to the study of mind. In E. Tobah \& R.J. Falmagne \& M.B. Parlee \& L.M. Martin \& e. A.S. Kapelman (Eds.), Mind and Social Practice: Selected Writings of Sylvia Scribner. (pp. 266-280.). Cambridge, UK: Cambridge University Press.

Seddon, T. (1999). Capacity building: Beyond state and market. Pedagogy, culture and society, 7(1), 35-53.

Somerville, M. (2002). Changing Masculine Work Cultures. Paper presented at the Envisioning practice -- Implementing change, Gold Coast.

Somerville, M., \& Bernoth, M. (2001). Safe Bodies: Solving a Dilemma in Workplace. Paper presented at the Knowledge Demands for the New Economy. 9th Annual International Conference on Post-compulsory Education and Training., Gold Coast, Queensland.

Suchman, L. (1997, 16 July 1997). from Interactions to Integrations: A reflection on the future of HCI, Key note Address. Paper presented at the Interact 97 - Discovering New Worlds of HCI, www.acs.org.au/president/1997/intrct97/suchman.htm.

Taylor, C. (1985). Human Agency and Language: Philosophical Papers 1. Cambridge: Cambridge University Press.

Valsiner, J. (1988). Developmental Psychology in the Soviet Union. Brighton: The Harvester Press.

Valsiner, J. (1994). Bi-directional cultural transmission and constructive sociogenesis. In W. de Graaf \& R. Maier (Eds.), Sociogenesis Re-examined (pp. 101-134). New York: Springer.

Valsiner, J. (1998). The Guided Mind: A Sociogenetic Approach to Personality. Cambridge, Mass: Harvard University Press.

Valsiner, J. (2000). Culture and Human Development. London: Sage Publications. 
Valsiner, J. and R. van der Veer (2000). The Social Mind: The construction of an idea. Cambridge, UK, Cambridge University Press.

Van Lehn, V. (1998). Towards a theory of impasse-driven learning. In H. Mandl \& A. Lesgold (Eds.), Learning issues for intelligent tutoring systems ). New York: (pp. pp. 31-32). New York: Springer-Verlag.

Weedon C (1997) Feminist Practice and Poststructuralist Theory. Blackwell Publishers, Massachuesetts

Wenger, E. (1998). Communities of Practice: Learning, Meaning, and Identity. Cambridge, UK: Cambridge University Press.

Wertsch, J. V. (1998). Mind as Action. New York: Oxford University Press.

Wertsch, J. W. (1991). A sociocultural approach to socially shared cognition. In L. B. Resnick \& J. M. Levine \& S. D. Teasley (Eds.), Perspectives on socially shared cognition (pp. 85-100). Washington DC: American Psychological Association.

Wright Mills, C. (1973). The meaning of work throughout history. In F. Best (Ed.), The future of work. Englewood Cliffs, NJ: Prentice Hall. 